\title{
Phase-Controllable Cobalt Phosphides induced through Hydrogel for Higher Lithium Storages
}

Tianxiao Guo, ${ }^{1, \ddagger}$ Congsen Wang, ${ }^{1,{ }^{\ddagger}}$ Hanwen Wu, ${ }^{1}$ Junqiao Lee, ${ }^{3}$ Guoqiang Zou, ${ }^{1}$ Hongshuai Hou, ${ }^{1}$ Xiaoyi Sun ${ }^{1 *}$, Debbie S. Silvester ${ }^{3 *}$ and Xiaobo $\mathbf{J i}^{1,2^{*}}$

1. College of Chemistry and Chemical Engineering, Central South University, Changsha 410083, China

2. School of Materials Science and Engineering, Zhengzhou University, Zhengzhou 450002, China

3. Curtin Institute for Functional Molecules and Interfaces, School of Molecular and Life Sciences, Curtin University, GPO Box U1987, Perth, WA 6845, Australia

* Corresponding authors. E-mail: xji@csu.edu.cn, d.silvester-dean@curtin.edu.au, xiaoyisun@csu.edu.cn.

$\$$ These authors contributed equally to this work. 


\section{ABSTRACT}

Transition metal phosphides (TMPs) have gained the increased attention in energy storage due to their potential to optimize electrochemical performances. However, their preparation routes usually require highly toxic and flammable phosphorus sources with strict reaction conditions. The existence of multiple energetically favorable stoichiometries also makes it a challenge to achieve phase-control of metal phosphides. In this work, we have been successfully realized the phase-controllable framework of cobalt phosphide from $\mathrm{Co}_{2} \mathrm{P}$ to $\mathrm{CoP}$ by employing semi-interpenetrating network (semiIPN) hydrogel as precursor. Interestingly, the semi-IPN hydrogel could serve as a selfassembly/sacrificing template to accomplish 3D space confinement, where PVPA was identified as a prominent phosphorous source due to its strong metal complexation ability and high thermal stability. Furthermore, this route is successfully extended to the synthesis of other TMPs including $\mathrm{Fe}_{2} \mathrm{P}, \mathrm{Ni}_{2} \mathrm{P}$ and $\mathrm{Cu}_{3} \mathrm{P}$. The specific structure of cobalt phosphides give rise to superior lithium storage performance, showing superior cycling stability (495.2 $\mathrm{mAh} \mathrm{g}^{-1}$ after 1000 cycles at $2.0 \mathrm{~A} \mathrm{~g}^{-1}$ ). This approach envisions a new outlook on exploitation of essential functional hydrogels for the creation of inorganic materials towards sustainable energy development. 


\section{INTRODUCTION}

Transition metal phosphides (TMPs) have attracted strong interest as anode materials for Li storage due to their high theoretical lithium storage capacities. ${ }^{1-2}$ They can also act as an effective catalyst for the hydrogen evolution reaction (HER), oxygen evolution reaction (OER) and oxygen reduction reaction (ORR) because of their high activity and low-cost. ${ }^{3-6}$ However, there are many challenges to developing an eco-friendly synthesis of metal phosphides due to the dangerous precursors, or the release of large amounts of toxic phosphine $\left(\mathrm{PH}_{3}\right)$ gas during their preparation process. ${ }^{7-9}$ Concentrated efforts devoted to exploring valid methods for preparing TMPs focus on two major strategies: solution-phase reaction and solid-phase reaction. ${ }^{10}$ Considering its strong coordination effect, tri-n-octylphosphine (TOP) is a common phosphorous source for many solution-phase reactions. Yet, the requirement for a high temperature organic solvent for the reaction system results in highly corrosive and flammable solution-phase reactions. ${ }^{11} \mathrm{PH}_{3}$, yielded from the thermal decomposition of $\mathrm{NaH}_{2} \mathrm{PO}_{2}$, is active in solid-phase phosphorization and can efficiently react with metal oxides or hydroxides to form TMPs. ${ }^{3-4,12}$ However, this method requires vent gas disposal in real time owing to the extreme toxicity of $\mathrm{PH}_{3}$. Besides, a large excess of phosphorous precursors must be utilized to ensure phase transformation from the metal to the phosphide. ${ }^{13-15}$ Temperature-programmed reduction of metal precursors is another type of solid-phase reaction; the resulted TMPs are generally macro-sized particles with poor electrochemical properties..$^{1,8}$

Integrating phosphorus with existing biomass has been demonstrated to be a novel tactic to produce functional metal phosphides. ${ }^{16}$ Nevertheless, the intricate process 
restricts its large-scale production. ${ }^{17}$ For further applications in energy conversion, the surface-area and architectures of TMPs must be better regulated. In addition, pure phase control of TMPs can allow for tunable chemical bonds; however, the existence of multiple energetically favorable stoichiometries makes this a challenge to achieve. ${ }^{18-19}$ Therefore, a simple protocol to obtain TMPs with accurate phase-selectivity and functional construction is highly desired for practical applications.

Hydrogels are composed of functional three-dimensional (3D) polymeric networks dispersed within a water-rich environment, and have attracted widespread attention in bionics, flexible electronics, biomedicine and energy converters. ${ }^{20-22} \mathrm{~A}$ semiinterpenetrating network (semi-IPN) hydrogel consists of a 3D polymer network where linear chains of other constituents physically interact with each other and also with the 3D network, often showing improved responsiveness and mechanical properties compared to a single network hydrogel. ${ }^{23-24}$ Advances in tunable morphologies and molecular architectures have produced nanostructured hydrogels with enhanced electrical conductivity and adjustable mechanical or surface properties which boosts the development of energy conversion technologies and electrocatalysis. ${ }^{25-27}$ Yu group developed an in-situ polymerization strategy to prepare a 3D nanostructured conductive gel framework electrode, ${ }^{28}$ which generated a framework that exhibited a hierarchically porous network with excellent conductivity, leading to a significant enhancement in electrochemical performances for lithium ion battery applications. However, little attention was paid to developing a methodology to prepare multipurpose hydrogelderived transition metal phosphides, since this is restricted by optimizing the 
phosphorous source and poor structure integration. ${ }^{29-30}$ Therefore, it remains an enormous challenge to prepared TMPs with integrated functionality and construction through the utilization of hydrogel precursors.

In this work, we present a novel strategy to overcome challenges in the design and preparation of TMPs using a PVPA-M ${ }^{\mathrm{n}+} /$ agar semi-IPN hydrogel, prepared by the solgel transition of agar in the presence of $\mathrm{M}^{\mathrm{n}+}$ adsorbed poly(vinylphosphonic acid) (PVPA) chains. Agar can be dissolved in hot water to form a gel consisting of a 3D microstructural network of helical bundles of linear macromolecular chains at room temperature, while PVPA (poly(vinylphosphonic acid)) has the ability to adsorb metal ions $\left(\mathrm{M}^{\mathrm{n}+}\right)$ - both of which have low toxicity. It is successfully demonstrated that semiIPN functional hydrogels could serve as self-assembly/sacrificing templates to accomplish 3D space confinement, resulting in a phase-controlled porous framework of $\mathrm{Co}_{\mathrm{x}} \mathrm{P}$ coated with thin carbon flakes (termed $\mathrm{Co}_{\mathrm{x}} \mathrm{P} / \mathrm{CFs}$ ) during in-situ phosphidation. This strategy circumvents the requirement of dangerous precursors and strict reaction conditions, which could be extended effectively to the preparation of $\mathrm{Fe}_{2} \mathrm{P}-\mathrm{C}, \mathrm{Ni}_{2} \mathrm{P}-\mathrm{C}$, and $\mathrm{Cu}_{3} \mathrm{P}-\mathrm{C}$ as well. The unique porous framework of $\mathrm{Co}_{\mathrm{x}} \mathrm{P} / \mathrm{CF}$ s could be employed as promising anode material, exhibiting superior lithium storage performance. The benefits of a hydrogel derived methodology for the formation of functional nanomaterials is significant and multifold; it presents a highly efficient strategy for the preparation of different metal phosphides with optimized morphology and performance, which envisions new outlook for the exploitation of functional hydrogels to produce inorganic nanomaterials for sustainable energy applications. 


\section{RESULT AND DISCUSSION}

As illustrated in Scheme 1, PVPA-Co ${ }^{2+} /$ agar semi-IPN hydrogels were obtained by mixing a PVPA-Co ${ }^{2+}$ complex solution with a hot agar solution, and subsequently utilized in the fabrication of $\mathrm{Co}_{\mathrm{x}} \mathrm{P} / \mathrm{CFs}$ through freeze-drying and pyrolysis processes. PVPA $\left(M_{\mathrm{n}}=24100\right)$ was successfully prepared through free-radical polymerization ${ }^{31}$ (NMR data in Fig S1 and GPC profile in Fig S2). In the presence of triethylamine, $\mathrm{Co}^{2+}$ ions could be effectively absorbed by PVPA through electrostatic interactions. ${ }^{32}$ A solidstate ${ }^{1} \mathrm{H}$ NMR spectrum of PVPA shows a single peak at $\delta=3.66-13.60 \mathrm{ppm}$. Multiple peaks in a lower field $(\delta=8.7-21.55 \mathrm{ppm})$ were present in the solid-state ${ }^{1} \mathrm{H}$ NMR spectrum of PVPA-Co ${ }^{2+}$ (Fig S3a), which is absent in neat PVPA, indicating $\mathrm{Co}^{2+}$ absorption by PVPA. ${ }^{33}$ Agar was dissolved in hot water to form linear macromolecular chains, which can self-assemble into a 3D network via helical bundles at room temperature. ${ }^{34-35}$ Fig S4 showed the image of as-prepared Semi-IPN gel. The obtained PVPA- $\mathrm{Co}^{2+} /$ agar semi-IPN hydrogel possesses a 3D self-supporting macroporous network after freeze drying (Fig S5), leading to the precursor for porous $\mathrm{Co}_{\mathrm{x}} \mathrm{P} / \mathrm{CFs}$ frameworks.

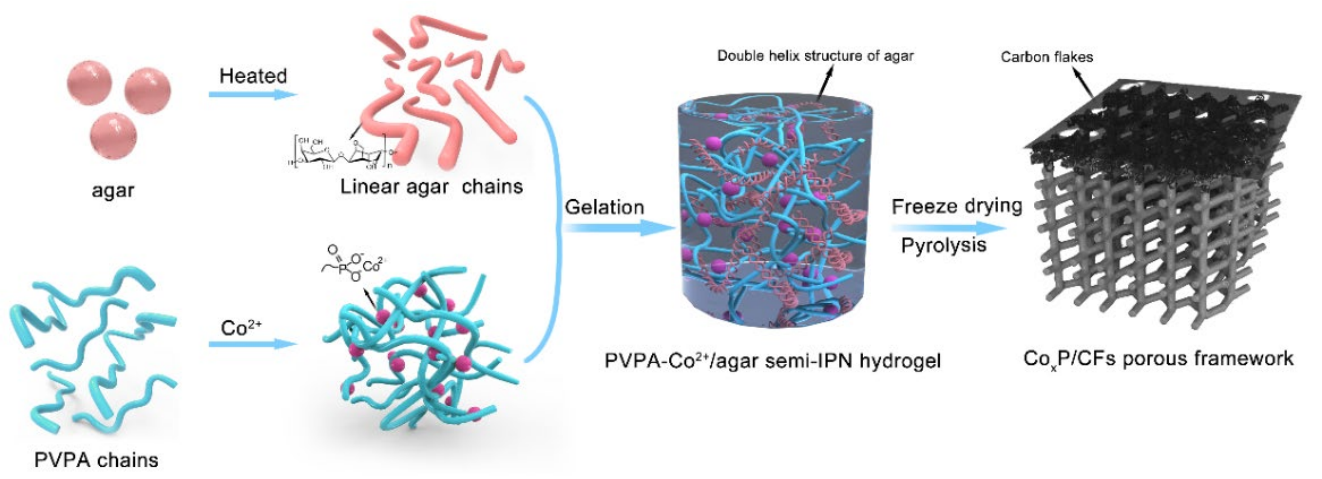

Scheme 1. Schematic diagram illustrating the preparation route of a $\mathrm{Co}_{x} \mathrm{P} / \mathrm{CFs}$ porous framework. 
The phase (stoichiometry) of cobalt phosphide could be manipulated by varying the phosphorous source/metal-ion molar ratio, confirmed by powder X-ray diffraction (XRD). XRD (Fig 1a) data shows the phase transformation from $\mathrm{Co}_{2} \mathrm{P}$ (JCPDS 32-0306) to CoP (JCPDS 29-0497), demonstrating the increased P/metal-ion molar ratio (from 1:2 to $2: 1$ ). As illustrated in Fig $1 \mathrm{~d}$ and 1f, it showed the crystal structure of $\mathrm{Co}_{2} \mathrm{P}$ and $\mathrm{CoP}$, more greatly, the connectivity of the anion sublattice of $\mathrm{Co}_{2} \mathrm{P}$ and $\mathrm{CoP}$ is integrated, where a deformation in the shape of the $\mathrm{P}$ sublattice is resulted from cation exchange reaction in nanocrystals with the transform amount of $\mathrm{Co}^{2+} \cdot 19,36-37$ Figs $1 \mathrm{~d}-\mathrm{f}$ show the morphology of the $\mathrm{Co}_{\mathrm{x}} \mathrm{P} / \mathrm{CFs}$. Both of them exist as a 3D porous framework, which is formed by interconnection of nanorods. Furthermore, it is clear that the porous framework is coated by thin carbon flakes; these are encapsulated in phase-diversified cobalt phosphide derived from the different agar content in the reaction system (where a higher $\mathrm{P} / \mathrm{metal}$-ion molar ratio corresponds to a lower agar content). As shown by the transmission electron microscopy (TEM) images (Fig1 d2, e2, f2), the $\mathrm{Co}_{\mathrm{x}} \mathrm{P} / \mathrm{CFs}$ frameworks have a rich porous morphology consisting of interlinked nanorods of 450 $\mathrm{nm}$ in diameter. Additionally, high-resolution TEM (HRTEM) images for CoP/CFs, $\mathrm{Co}_{2} \mathrm{P} / \mathrm{CoP} / \mathrm{CFs}$, and $\mathrm{Co}_{2} \mathrm{P} / \mathrm{CFs}$ nanoparticles display high levels of crystallinity, as revealed by the presence of lattice fringes. The marked lattice spacings of ca. $0.285 \mathrm{~nm}$ and $0.186 \mathrm{~nm}$ in Fig1 d3 correspond to the (120) and (031) lattice planes of orthorhombic $\mathrm{Co}_{2} \mathrm{P}$, respectively. The interplanar $d$-spacings are measured to be ca. $0.205 \mathrm{~nm}$ and $0.231 \mathrm{~nm}$ in Fig $1 \mathrm{e} 3$ according to the (130) lattice plane of $\mathrm{Co}_{2} \mathrm{P}$ and (201) lattice plane of CoP, respectively. In Fig $1 \mathrm{f}$, the gauged lattice spacings of ca. 
$0.231 \mathrm{~nm}$ and $0.119 \mathrm{~nm}$ are identified as the (201) and (123) lattice planes of orthorhombic CoP.

The feasibility of the phase-control of cobalt phosphide with our strategy is us tfurther investigated with the phosphorous source (PVPA) itself, which presents a highly crosslinked structure containing multiple phosphonate-ions. ${ }^{38-39}$ PVPA chain can simultaneously attach itself to multiple sites, resulting in higher entropic stability to metal ion; while maintaining a relatively fixed $\mathrm{P} /$ metal-ion ratio. $^{40-41}$ This overcomes the challenge of multiple energetically favorable stoichiometries, thus enabling effective phase-control of cobalt phosphides. ${ }^{19}$ Unlike the hypertoxic and costly precursors mentioned above, the use of PVPA as a phosphorous source would be an effective tool to prepare metal phosphides.

The compositional distribution of $\mathrm{Co}_{\mathrm{x}} \mathrm{P} / \mathrm{CFs}$ have been further investigated. Fig $1(\mathrm{~d} 4$, e4, f4) shows the Energy-dispersive spectroscopy (EDX) elemental mapping of characteristic $\mathrm{CoP} / \mathrm{CFs}, \mathrm{Co}_{2} \mathrm{P} / \mathrm{CoP} / \mathrm{CFs}, \mathrm{Co}_{2} \mathrm{P} / \mathrm{CFs}$ that were randomly chosen for component analysis. It reveals a uniform distribution of cobalt, phosphorus, and carbon. EDX was carried out to characterize the chemical compositions of $\mathrm{Co}_{\mathrm{x}} \mathrm{P} / \mathrm{CFs}$ hybrid materials. The obtained result (Figure S6) demonstrated the presence of $\mathrm{Co}_{2} \mathrm{P}, \mathrm{Co}_{\mathrm{x}} \mathrm{P}$, and $\mathrm{CoP}$ with approximate $\mathrm{Co} / \mathrm{P}$ ratios ranging from 2:1 to $1: 1$. Raman spectra (Fig $1 \mathrm{~b}$ ) of $\mathrm{CoP} / \mathrm{CFs}, \mathrm{Co}_{2} \mathrm{P} / \mathrm{CoP} / \mathrm{CFs}, \mathrm{Co}_{2} \mathrm{P} / \mathrm{CFs}$ show the typical $\mathrm{D}$ bond and $\mathrm{G}$ bond located around at 1350 and $1580 \mathrm{~cm}^{-1}$, showing the existence of carbon flakes. X-ray photoelectron spectroscopy (XPS) was employed to uncover specific surface information on the $\mathrm{Co}_{\mathrm{x}} \mathrm{P} / \mathrm{CFs}$. The survey of XPS spectra (Figures S7 a1, b1 and c1) 
reveal the existence of $\mathrm{Co}, \mathrm{P}, \mathrm{C}$, in line with the EDX mapping result. XPS peakdifferentation imitating analysis of $\mathrm{P} 2 \mathrm{p}$ (Fig 1c) indicated the presence of P-O bonds (oxidized $\mathrm{P}$ species) and Co-P bonds in $\mathrm{Co}_{\mathrm{x}} \mathrm{P} / \mathrm{CFs}{ }^{42}$ All C 1s spectra (Figure S7 a3, b3 and c3) of $\mathrm{Co}_{2} \mathrm{P} / \mathrm{CFs}, \mathrm{Co}_{2} \mathrm{P} / \mathrm{CoP} / \mathrm{CFs}, \mathrm{CoP} / \mathrm{CFs}$ can be deconvoluted into four peaks, which pertain to O-C-O, C-N, C-O, C-C/C $=\mathrm{C}$ bonds, respectively. ${ }^{43}$ Comparison of the binding energy of $\mathrm{Co} 2 \mathrm{p}_{3 / 2}$ (Figure $\mathrm{S} 7 \mathrm{a} 2$, b2 and c2) in $\mathrm{Co}_{2} \mathrm{P} / \mathrm{CFs}, \mathrm{Co}_{2} \mathrm{P} / \mathrm{CoP} / \mathrm{CFs}$, $\mathrm{CoP} / \mathrm{CFs}$, reveals a decreasing trend, which can be attributed to the reduction of $\mathrm{P}$ content, giving rise to the stronger bond strength between $\mathrm{Co}$ and $\mathrm{P}$ atoms, and agrees well with previous work. ${ }^{44-45}$ The $3 \mathrm{D}$ porous framework of $\mathrm{Co}_{\mathrm{x}} \mathrm{P} / \mathrm{CFs}$ is further demonstrated by $\mathrm{N}_{2}$ absorption-desorption isotherms (Fig S8); the BTH curves of $\mathrm{Co}_{2} \mathrm{P} / \mathrm{CFs}, \mathrm{Co}_{2} \mathrm{P} / \mathrm{CoP} / \mathrm{CFs}, \mathrm{CoP} / \mathrm{CFs}$ show a typical hysteresis loop that reveals the mesporous character of the $\mathrm{Co}_{\mathrm{x}} \mathrm{P}$ framework. Furthermore, the Barrett-Joyner-Halenda (BJH) pore-size distribution curves of $\mathrm{Co}_{\mathrm{x}} \mathrm{P} / \mathrm{CFs}$ show relatively broad size-distribution of mesopores, which is well consistent with the TEM result (Fig 1 (d2, e2, f2). The high surface area of the $\mathrm{Co}_{\mathrm{x}} \mathrm{P} / \mathrm{CFs}$ porous framework would be highly beneficial for applications in energy storage and catalysis, which can promote contact of the electrode with electrolytes, as well as buffer the mechanical stress, leading to the pronounced improvement of cycle life and rate performances when applied as an anode material. ${ }^{46}$ Furthermore, this porous framework can provide more accessible active sites which facilitate mass transport when applied as a catalyst material. ${ }^{47}$ 

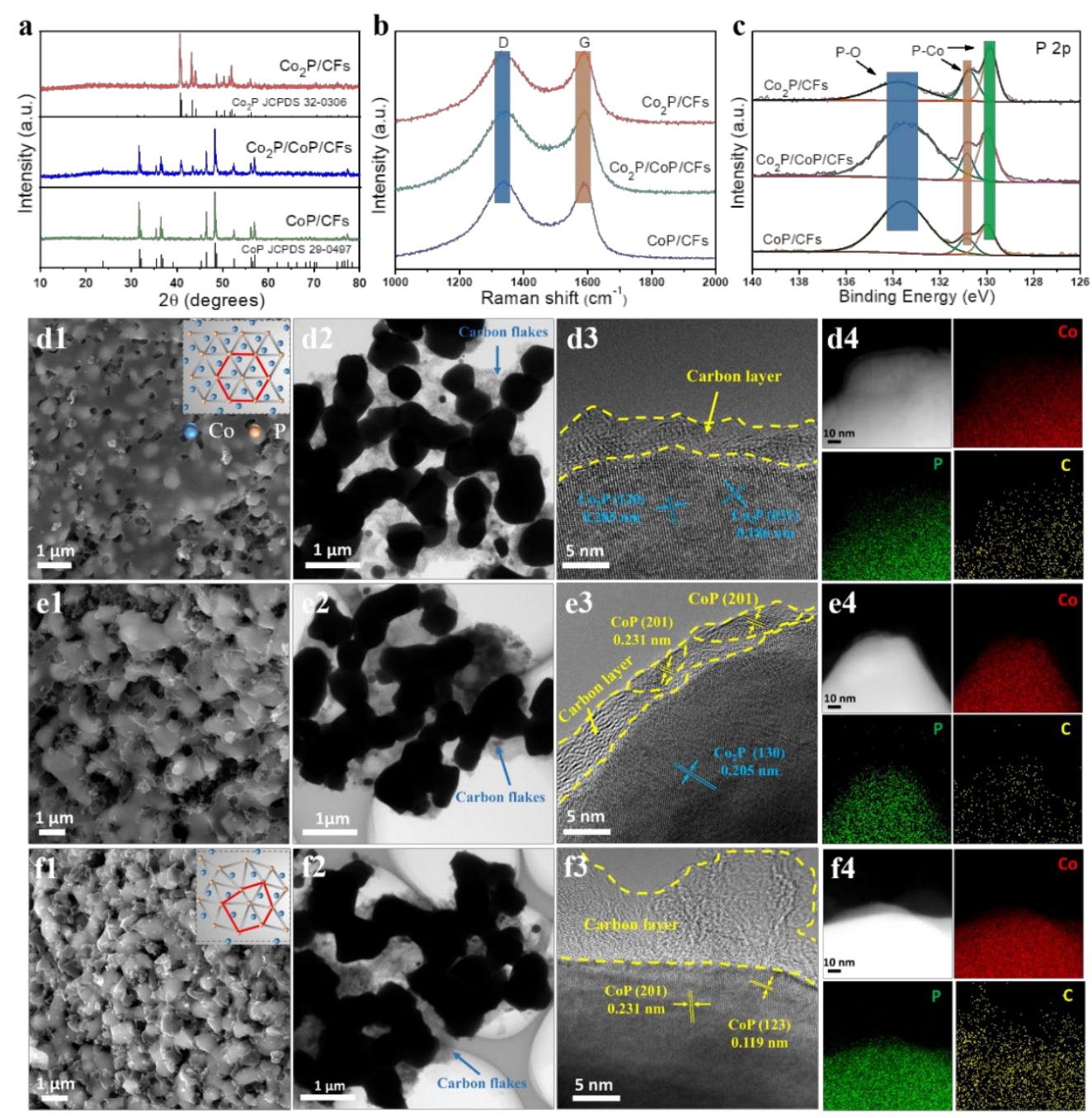

Fig 1. (a) XRD patterns, (b) Raman spectra and (c) P 2p XPS spectra of $\mathrm{Co}_{2} \mathrm{P} / \mathrm{CFs}$,

$\mathrm{Co}_{2} \mathrm{P} / \mathrm{CoP} / \mathrm{CFs}, \mathrm{CoP} / \mathrm{CFs}$ samples. SEM images (d1, e1, f1), TEM images (d2, e2, f2), HRTEM images (d3, e3, f3) and elemental mapping (d4, e4, f4) of $\mathrm{Co}_{2} \mathrm{P} / \mathrm{CFs}$, $\mathrm{Co}_{2} \mathrm{P} / \mathrm{CoP} / \mathrm{CFs}, \mathrm{CoP} / \mathrm{CFs}$, respectively.

\section{REACTION MECHANISM}

For this hydrogel system, PVPA acts as an effective phosphorous source to adsorb cobalt ions, and agar works as a gelator, which interacts to form a semi-IPN hydrogel. The porous framework resulted from this semi-IPN hydrogel-based reaction system have inspired us to explore the effect of agar and polymer (PVPA) in the pyrolysis process and the chemical transformation from polymer aerogel to inorganic crystals. 
First, our control experiments emphasize the exact role of agar, here termed as Co-P-N $\left(0.5,1\right.$ and 2 represent the molar ratio of $\left.\mathrm{P} / \mathrm{Co}^{2+}\right)$. Without agar, the XRD patterns of the formed products (Fig 2a) present a mixture of impurity phase of phosphate, showing that the double-helix agar chain serves as a reductant during the annealing process. Meanwhile, the as-obtained samples would have a shape of unordered particles aggregated together (Fig 2 b-c). It was also confirmed that a semi-IPN hydrogel of double-helix agar chain and PVPA could act as a 3D scaffold incorporated with metal ions, accomplishing 3D space confinement that ensures suitable conditions for the reaction-diffusion of metal ion with phosphate sources. ${ }^{48-49}$ Moreover, the agar/PVPA$\mathrm{Co}^{2+}$ semi-IPN serves as a supporting network to promote the formation of the $\mathrm{Co}_{x} \mathrm{P}$ porous framework in three dimensions. The semi-IPN derived carbon flakes, which cover the framework, could effectively relieve volume expansion and facilitate mass transport when used as electrode materials.

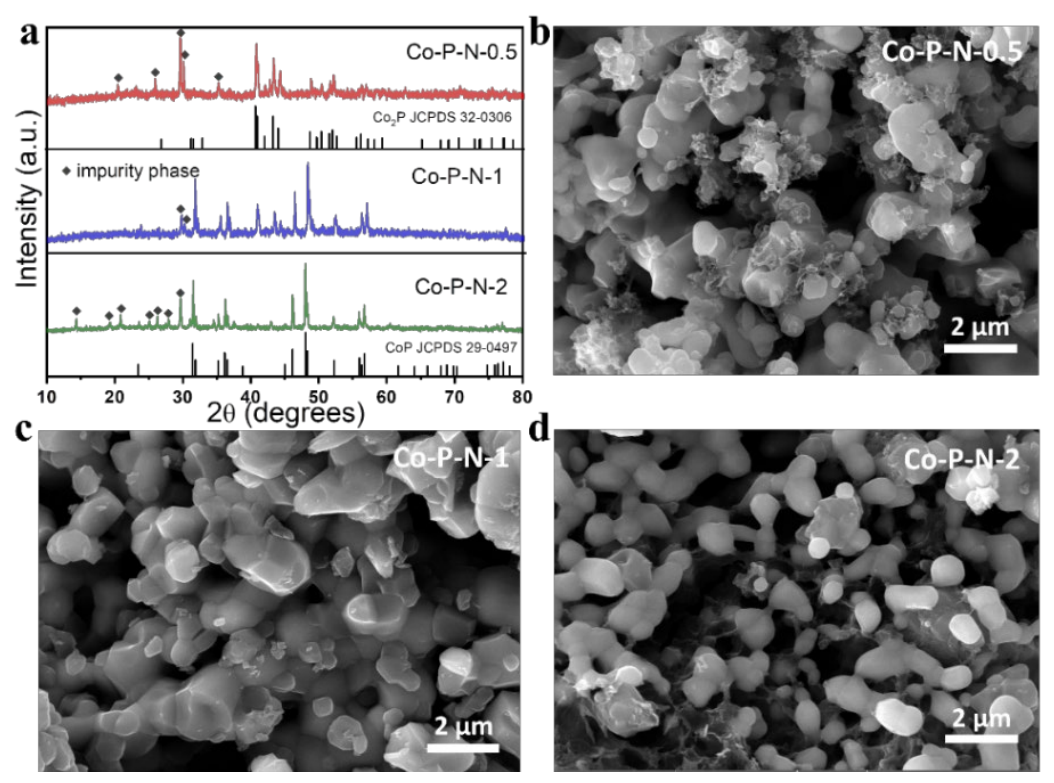

Fig 2. (a) XRD patterns of Co-P-N-0.5, Co-P-N-1 and Co-P-N-2. SEM images of (b) Co-P-N-0.5, (c) Co-P-N-1 and (d) Co-P-N-2. 
In addition, the control experiments was undertaken while employing the monomer VPA as the phosphorous source to observe the effect of the use of the polymeric form on the porous framework formation. As seen in Fig 3, under the same conditions (especially for the same initial $\mathrm{P} / \mathrm{Co}^{2+}$ ratio), $\mathrm{XRD}$ data of the resultant product based on the use of the monomer VPA as a phosphorous source, in different $\mathrm{P} / \mathrm{Co}^{2+}$ ratios (termed as Co-P-M-0.5, Co-P-M-1, Co-P-M-2 respectively) presents a number of phosphate impurities when the $\mathrm{P} / \mathrm{Co}^{2+}$ ratio was 0.5 , and some $\mathrm{Co}_{2} \mathrm{P}$ phase impurities when the $\mathrm{P} / \mathrm{Co}^{2+}$ ratio was 2 . This is different when utilizing the polymeric PVPA as the $\mathrm{P}$ source at the same ratio of $\mathrm{P} / \mathrm{Co}^{2+}(\mathrm{CoP} / \mathrm{CFs})$, which showed a pure CoP phase. SEM images (Fig 3 b-c) of Co-P-M revealed a significant difference in the morphology of the $\mathrm{Co}_{\mathrm{x}} \mathrm{P} / \mathrm{CFs}$. Co-P-M presented a structure similar to plastic foam with aggregated particles, while $\mathrm{Co}_{\mathrm{x}} \mathrm{P} / \mathrm{CFs}$ showed a porous framework. Therefore it is proposed that a higher entropic stability between the PVPA chain and $\mathrm{Co}^{2+}$ could minimize the losses of phosphorous constituent that promotes the reduction reaction during chemical conversion. Most notably, the PVPA- $\mathrm{Co}^{2+} /$ agar semi-IPN hydrogels also brings 3D space confinement, generating the desired porous framework. 


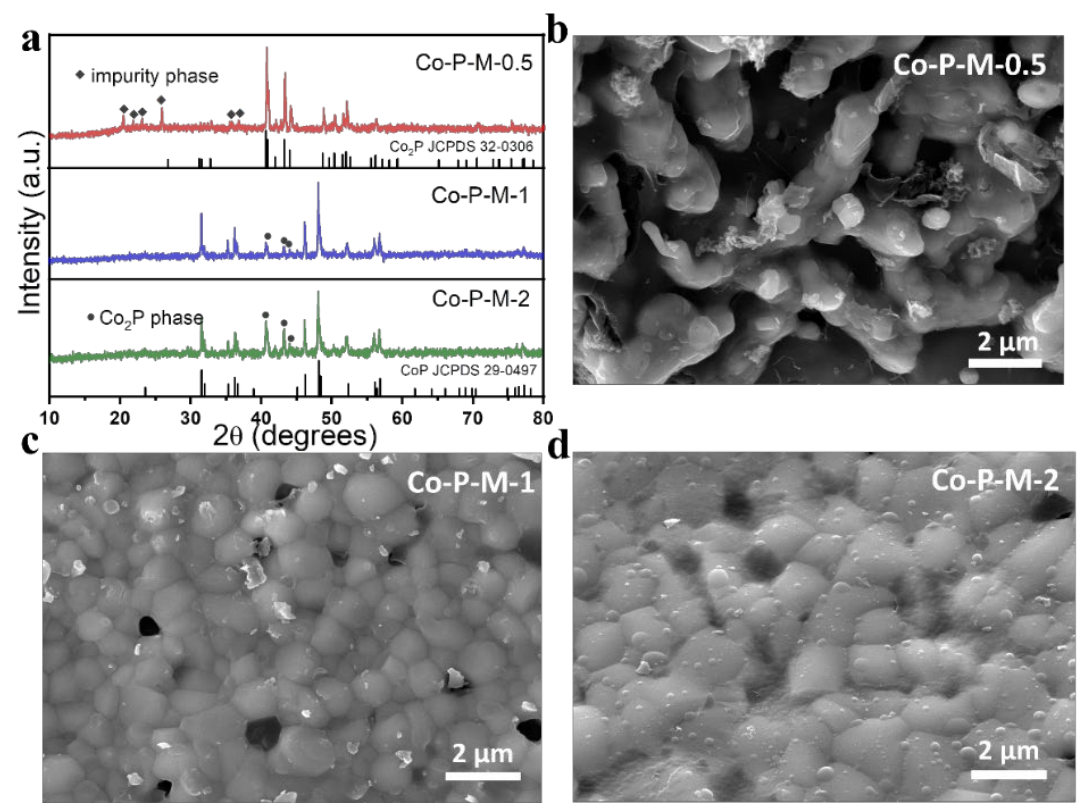

Fig 3. (a) XRD patterns of Co-P-M-0.5, Co-P-M-1 and Co-P-M-2. SEM images of (b) Co-P-M-0.5, (c) Co-P-M-1 and (d) Co-P-M-2.

Characterization of the structural evolution and chemical transformation from the polymer precursor to the functional framework during the annealing process is a major challenge in this work. A more in-depth understanding of the formation pathway would enable the prediction of metal phosphide materials resulted from this hydrogel system, which could be extended to the fabrication of other inorganic materials by utilizing this proposed protocol. Here, the formation mechanism of $\mathrm{Co}_{\mathrm{x}} \mathrm{P} / \mathrm{CFs}$ porous framework was examined in details. High temperature ex-situ XRD was carried out to measure the phase transformation of $\mathrm{CoP} / \mathrm{CFs}$ and Co-M-2 during heating. As shown in Fig 4a and Fig $4 \mathrm{~b}$, it shows the same phase transformation for both $\mathrm{CoP} / \mathrm{CF}$ and Co-M-2 from $700{ }^{\circ} \mathrm{C}$ to $900{ }^{\circ} \mathrm{C}$ over two stages. In the first stage, it shows a transformation from the amorphous phase to $\mathrm{Co}\left(\mathrm{PO}_{3}\right)_{2}$ (JCPDS 27-1102), and in the following stage, it undergoes a phase transition from $\mathrm{Co}\left(\mathrm{PO}_{3}\right)_{2}$ to cobalt phosphides. 
A detailed analysis of XRD data of $\mathrm{CoP} / \mathrm{CFs}$ and Co-M-2 at different temperatures exhibits pronounced differences. At $750{ }^{\circ} \mathrm{C}, \mathrm{CoP} / \mathrm{CFs}-750$ and Co-M-2-750 both show a crystalline $\mathrm{Co}\left(\mathrm{PO}_{3}\right)_{2}$ phase without the existence of any other crystal phase. At 800 ${ }^{\circ} \mathrm{C}$, the XRD pattern of $\mathrm{CoP} / \mathrm{CFs}-800$ and $\mathrm{Co}-\mathrm{M}-2-800$ show the presence of $\mathrm{Co}\left(\mathrm{PO}_{3}\right)_{2}$ phase still present as the major phase, and there are a few peaks corresponding to the CoP phase. Meanwhile, $\mathrm{CoP} / \mathrm{CFs}-800$ produced more peaks from the CoP phase compared to the Co-M-2-800 samples. At $850^{\circ} \mathrm{C}$, the XRD patterns of $\mathrm{CoP} / \mathrm{CFs}-850$ and Co-M-2-850 exhibit disparity, where the $\mathrm{CoP} / \mathrm{CFs}-850$ products demonstrates the majority of the $\mathrm{CoP}$ phase with the $\mathrm{Co}\left(\mathrm{PO}_{3}\right)_{2}$ phase are greatly diminished, however, the majority phase of Co-M-2-850 still remain as $\mathrm{Co}\left(\mathrm{PO}_{3}\right)_{2}$. At $900{ }^{\circ} \mathrm{C}$, the $\mathrm{XRD}$ pattern of $\mathrm{CoP} / \mathrm{CFs}-900$ shows the pure crystalline CoP phase, while the XRD pattern of CoM-2-900 exhibits a mixture of $\mathrm{Co}_{2} \mathrm{P}$ and $\mathrm{CoP}$.

Meanwhile, the ex-situ SEM (Fig 4e) is employed to measure the structural evolution of $\mathrm{CoP} / \mathrm{CFs}$ and $\mathrm{Co}-\mathrm{M}-2$ during heating. SEM images of the transformation of $\mathrm{CoP} / \mathrm{CFs}$ and Co-M-2 show a more porous structure with increasing temperature, which can be attributed to the release of gaseous molecules, which is different from Co-M-2, where SEM images of $\mathrm{CoP} / \mathrm{CFs}$ at all temperatures exhibited relatively higher porosity. Note that the morphology transition of $\mathrm{CoP} / \mathrm{CFs}$ is appeared at $850{ }^{\circ} \mathrm{C}$ when it undergoes the dominant phase transformation from $\mathrm{Co}\left(\mathrm{PO}_{3}\right)_{2}$ to $\mathrm{CoP}$. At this point, $\mathrm{CoP} / \mathrm{CFs}$ can be obtained at $900{ }^{\circ} \mathrm{C}$ by using a self-assembly/sacrificing template carbon framework, and crystallization of $\mathrm{CoP}$ with the carbon source of $\mathrm{PVPA}-\mathrm{Co}^{2+} /$ agar semi-IPN hydrogel serving as a reducing agent. Furthermore, the diverse phase transformation 
between $\mathrm{CoP} / \mathrm{CFs}$ and Co-M-2 is explored by analyzing the pivotal temperature point of $750{ }^{\circ} \mathrm{C}$. Fig $4 \mathrm{c}$ and $4 \mathrm{~d}$ display the XRD refinement of CoP/CFs-750 and Co-P-M750 powders, showing that both $\mathrm{CoP} / \mathrm{CFs}-750$ and Co-P-M-75 have a monoclinic crystal phase, in which CoP/CFs-750 exhibit cell parameters of $\mathrm{a}=11.8561 \AA, \mathrm{b}=8.3250 \AA$ and $\mathrm{c}=9.9486 \AA$, Co-P-M-75 exhibit cell parameters of $\mathrm{a}=11.8090 \AA, \mathrm{b}=8.2970 \AA$ and $\mathrm{c}=9.9230 \AA$.
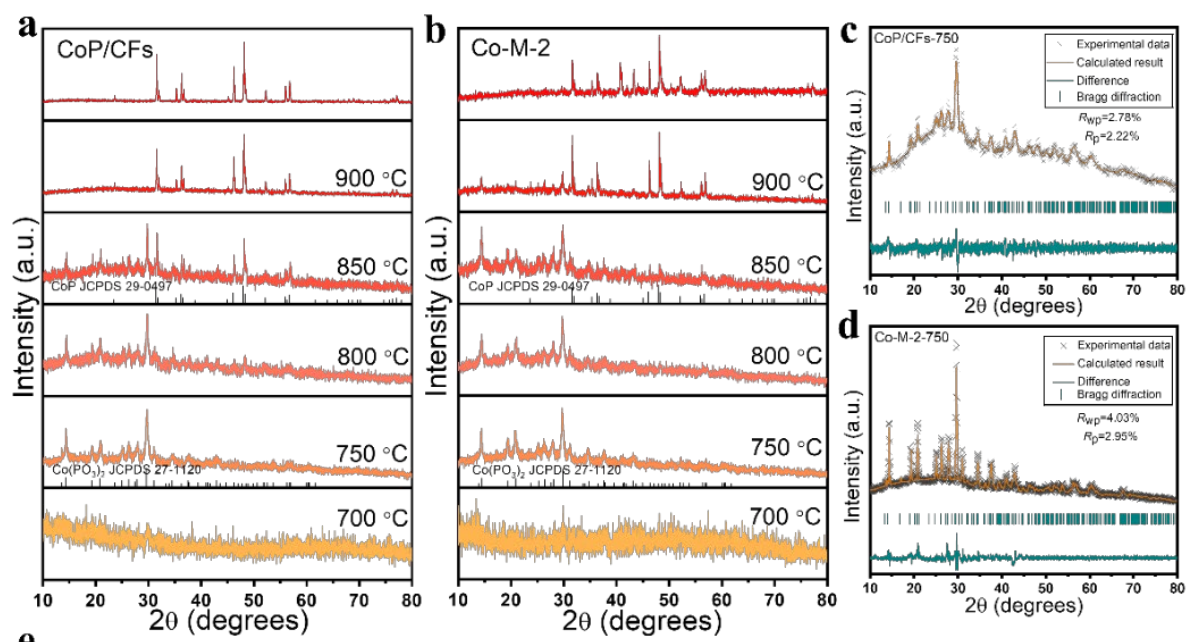

$\mathbf{e}$

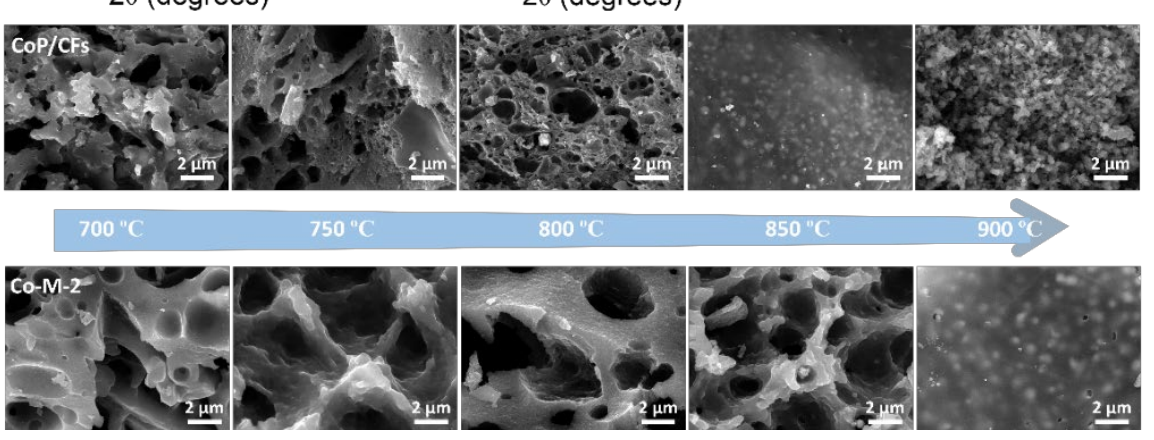

Fig 4. High temperature ex-situ XRD patterns of (a) CoP/CFs and (b) Co-M-2. Rietveld refinement of XRD patterns of (c) CoP/CFs-750 and (d) Co-M-2-750. (e) SEM images of the structural evolution of $\mathrm{CoP} / \mathrm{CFs}$ and $\mathrm{Co}-\mathrm{M}-2$ with increasing temperature.

Fig 5c and 5d show the TEM and HRTEM images of CoP/CFs-750 and Co-M-2-750, respectively. Compared with Co-M-2-750, CoP/CFs-750 exhibit a "looser" morphology, which stems from the 3D space confinement of the semi-IPN hydrogel precursor. Both 
the $\mathrm{CoP} / \mathrm{CFs}-750$ and Co-M-2-750 samples reveal a hetero-phase composed of amorphous and crystalline domains. It is worth noting that CoP/CFs-750 show a higher percentage of crystalline areas. Additionally, the Co 2p (Fig 5a) and P 2p (Fig 5b) peaks of $\mathrm{CoP} / \mathrm{CFs}-750$ is gradually shifted to a lower binding energy in comparison to Co-M2-750, suggesting that the Co present in CoP/CFs-750 contributes less electrons than Co-M-2-750, leading to a greater tendency to phase transform from $\mathrm{Co}\left(\mathrm{PO}_{3}\right)_{2}$ to $\mathrm{CoP}$. The observation that the crystalline nanosheet has a lower binding energy, agreeing well with previous reports. ${ }^{50-51}$
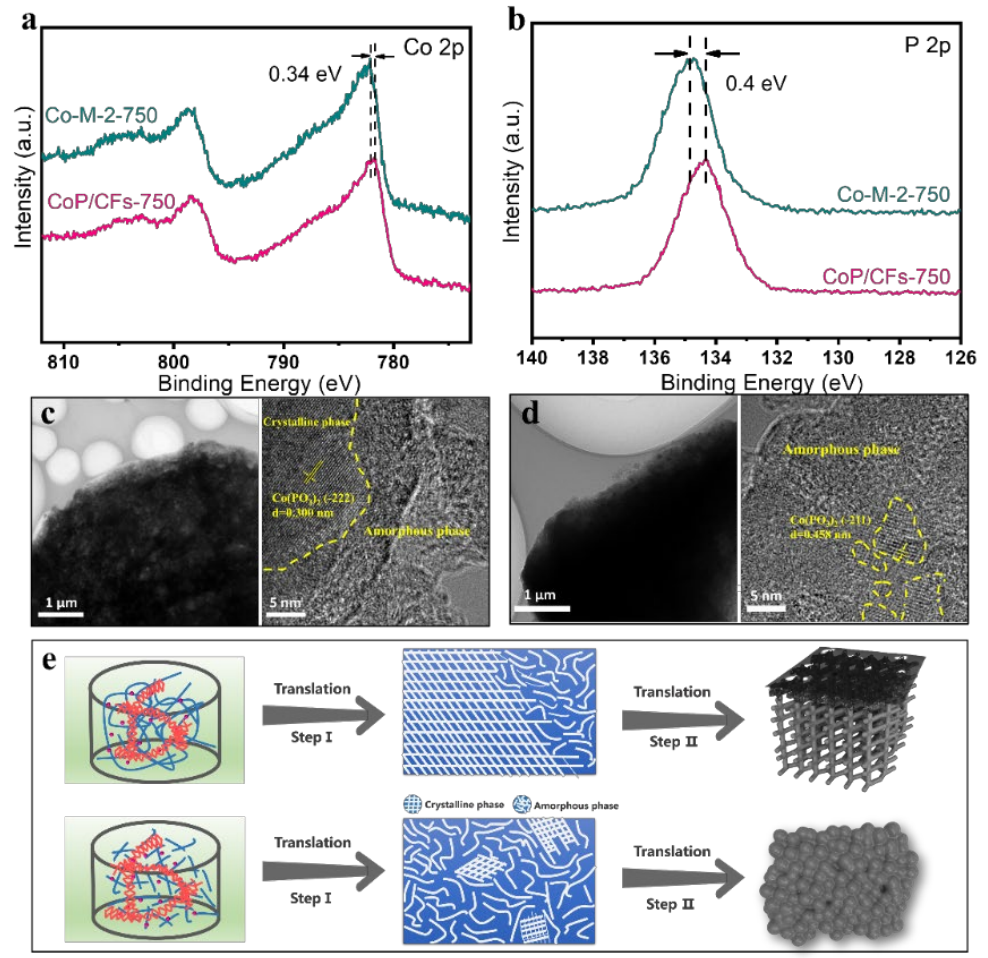

Fig 5. XPS spectra of Co $2 p(a)$ and $P 2 p(b)$ of CoP/CFs-750 and Co-M-2-750. SEM image and TEM image of (c) CoP/CFs-750 and (d) Co-M-2-750. (e) Schematic illustration of the structural evolution and chemical transformation routes of $\mathrm{CoP} / \mathrm{CFs}$ and Co-M-2. 
Based on the analysis above, it is proposed that the successful in-situ phosphidation methodology of preparing cobalt phosphides rests on the following facts: Firstly, the PVPA chain exhibits higher entropic stability to metal ions, overcoming the issue of multiple energetically favorable stoichiometries to achieve better phase control and fuller phase conversion of cobalt phosphides. Secondly, the PVPA polymer minimise the losses of phosphorous, promoting the formation of crystalline domains, and increasing the tendency towards phase transformation. Thirdly, PVPA-Co ${ }^{2+} /$ agar semiIPN hydrogels serve as self-assembly and self-sacrificing templates, accomplishing 3D space confinement.

In light of this effective in-situ phosphidation of the semi-IPN hydrogel, and the fact that the PVPA chains can also adsorb other metal ions by electrostatic interactions, it is not surprising that this method can be applied to other metals as well. In the following, iron $(\mathrm{Fe})$, nickle $(\mathrm{Ni})$, and copper $(\mathrm{Cu})$ in this work are further explored. As seen in Fig 6a, the XRD data revealed the formation of $\mathrm{Fe}_{2} \mathrm{P}$ (JCPDS 51-0943), $\mathrm{Ni}_{2} \mathrm{P}$ (JCPDS $03-$ 0953), $\mathrm{Cu}_{3} \mathrm{P}$ (JCPDS 02-1263), without impurities. Meanwhile, the Raman spectra (Fig 6b) of $\mathrm{Fe}_{2} \mathrm{P}-\mathrm{C}, \mathrm{Ni}_{2} \mathrm{P}-\mathrm{C}$, and $\mathrm{Cu}_{3} \mathrm{P}-\mathrm{C}$ present the representative $\mathrm{D}$ bond and $\mathrm{G}$ bond which confirms the well-integrated carbon structure and metal phosphides. In line with the $\mathrm{Co}_{\mathrm{x}} \mathrm{P} / \mathrm{CFs}$, P 2p XPS spectra (Fig 6c) of $\mathrm{Fe}_{2} \mathrm{P}-\mathrm{C}, \mathrm{Ni}_{2} \mathrm{P}-\mathrm{C}$, and $\mathrm{Cu}_{3} \mathrm{P}-\mathrm{C}$ can also be deconvoluted into three peaks which are attributed to $\mathrm{P}-\mathrm{O}$ bonds and Co-P bonds, and the $\mathrm{C}$ 1s spectrum (Fig S9c, S10c, S11c) of the resulting samples also show O-C-O, C$\mathrm{N}, \mathrm{C}-\mathrm{O}$ and $\mathrm{C}-\mathrm{C} / \mathrm{C}=\mathrm{C}$ bonds. Importantly, their BTH test (Fig 3d) shows the highly porous construction, with specific surface areas of $85.34,37.93,48.27 \mathrm{~m}^{2} / \mathrm{g}$, 
respectively. Furthermore, the $\mathrm{BJH}$ volume and pore-size measurement show a relatively broad distribution of mesporores (Fig S12). The above analysis assumes uniformity of the pores and the integrated carbon matrix. It is noted that this technique can potentially be further extended to the fabrication of other functional inorganic nanomaterials that applied to energy conversion and storage which it become a urgent aim nowadays. ${ }^{6,52-54}$
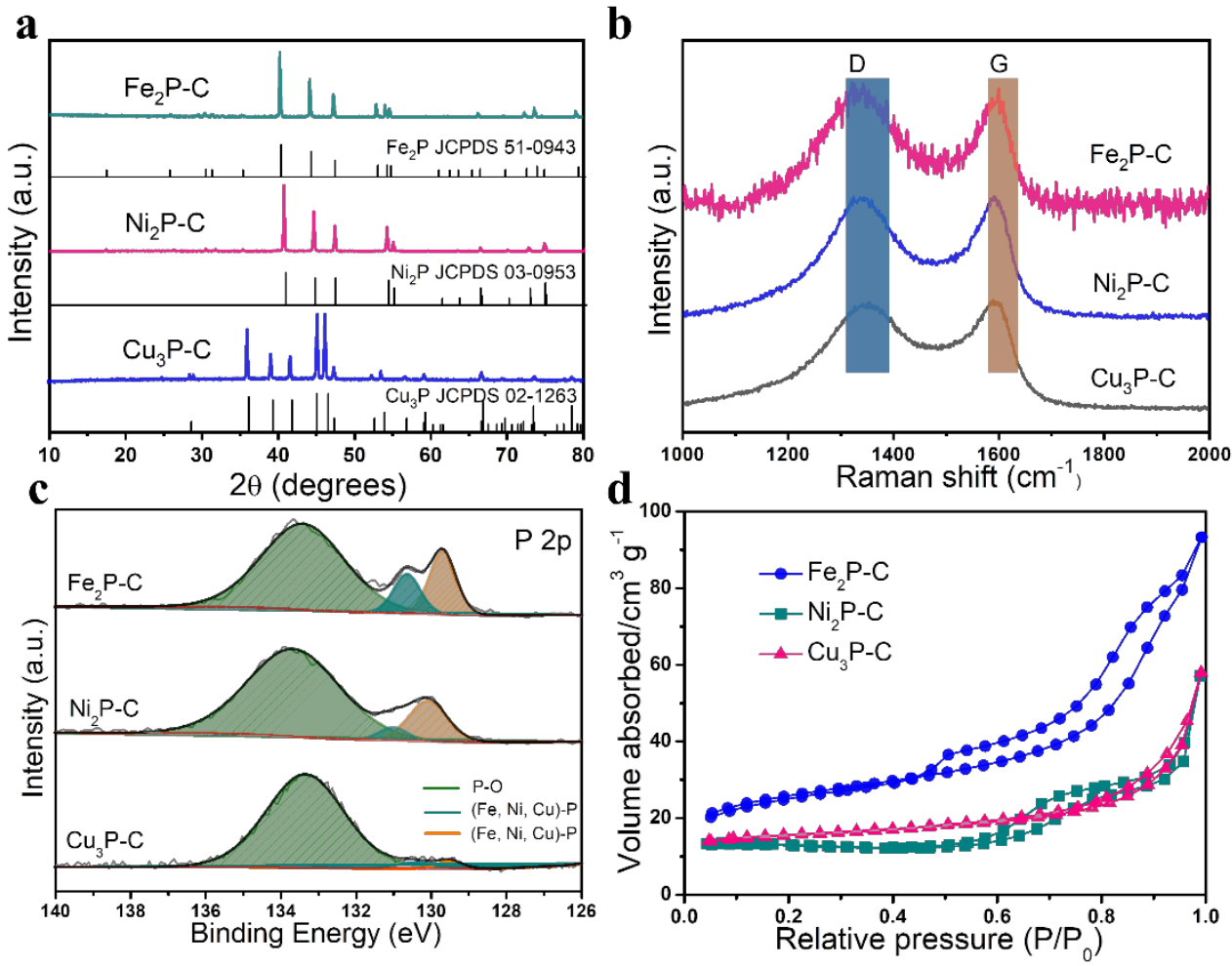

Fig 6. (a) XRD patterns, (b) Raman spectra, (c) P 2p XPS spectra and (d) $\mathrm{N}_{2}$ adsorption/desorption isotherms of $\mathrm{Fe}_{2} \mathrm{P}-\mathrm{C}, \mathrm{Ni}_{2} \mathrm{P}-\mathrm{C}$ and $\mathrm{Cu}_{3} \mathrm{P}-\mathrm{C}$

\section{ELECTROCHEMICAL CHARACTERIZATION}

The unique porous framework of $\mathrm{Co}_{\mathrm{x}} \mathrm{P} / \mathrm{CFs}$ plays a crucial role in its excellent electrochemical performance. When employed as an electrode material for lithium ion batteries (LIBs), it shows a long cycle life and high rate capability. Cyclic voltammetry 
(CV) curves of $\mathrm{CoP} / \mathrm{CFs}$ show a reversible lithiation potential located at $1.1 \mathrm{~V}$ which is attributed to the reaction of $\mathrm{Li}^{+}$and $\mathrm{CoP}$ on the first discharge, then remains at $0.43 \mathrm{~V}$ in the following cycles (Fig 7a). ${ }^{2,15}$ Delithiation occurs at $1.1 \mathrm{~V}\left(\mathrm{vs} \mathrm{Li}^{+} / \mathrm{Li}\right) . \mathrm{Co}_{2} \mathrm{P} / \mathrm{CFs}$ and $\mathrm{Co}_{2} \mathrm{P} / \mathrm{CoP} / \mathrm{CFs}$ show a similar electrochemical reaction mechanism confirmed by $\mathrm{CV}$ measurements (Fig S13). The interrelated charge-discharge curves of $\mathrm{CoP} / \mathrm{CFs}$ at $0.2 \mathrm{~A} \mathrm{~g}^{-1}$ are in line with the characteristic peaks present in the CV curves. Accordingly, the $\mathrm{CoP} / \mathrm{CFs}$ electrode delivers discharge and charge capacities of 1326.3 and 1024.0 $\mathrm{mAh} \mathrm{g}^{-1}$ in the first cycle, with a high initial Coulombic efficiency (ICE) of 77.2\%. This is an unconventionally high ICE compared to other anode materials that utilize metal phosphides (Table S1).

Fig $7 \mathrm{~b}$ displays the cycling property of $\mathrm{CoP} / \mathrm{CFs}$ at a current density of $0.2 \mathrm{~A} \mathrm{~g}^{-1}$. The electrode shows a high reversible capacity of $688.9 \mathrm{mAh} \mathrm{g}^{-1}$ after 100 cycles. Similar charge-discharge curves for each tenth cycle (Fig S14a) indicates good cycling stability of the $\mathrm{CoP} / \mathrm{CFs}$ electrode. The rate performance is revealed in Fig $7 \mathrm{~g}$, and shows high capacities of 819.1, 658.4, 578.9, 532.6, $492.7 \mathrm{mAh} \mathrm{g}^{-1}$ at $0.1,0.2,0.5,1.0,2.0 \mathrm{~A} \mathrm{~g}^{-1}$, respectively. Remarkably, the $\mathrm{CoP} / \mathrm{CFs}$ electrode exhibits excellent long cycling stability at a high current density of $2.0 \mathrm{~A} \mathrm{~g}^{-1}$, retaining a stable capacity of $495.2 \mathrm{mAh}$ $\mathrm{g}^{-1}$ after 1000 cycles (Fig 7h).

The prominent electrochemical performance of the $\mathrm{CoP} / \mathrm{CF}$ s electrode inspired us to explore the reaction kinetics through $\mathrm{CV}$ profiles at different scan rates (Fig 7d). As shown in Fig 7e, the capacitive contribution is predominant over the whole scan rate range. The b-values of peak A and Peak B were about 0.73 and 0.65 (Fig S15b) 
respectively, proving a pseudo-capacitive dominance. ${ }^{55-56}$ Additionally, the capacitive ratio gradually increases from $50.9 \%\left(0.2 \mathrm{mV} \mathrm{s}^{-1}\right)$ to $93.8 \%\left(1 \mathrm{mV} \mathrm{s}^{-1}\right)$ (Fig $\left.7 \mathrm{f}\right)$. The rate capability could benefit from the strong capacitive feature which mainly stems from the distinct construction with shuttling paths. ${ }^{55,57-58}$ Meanwhile, $\mathrm{Co}_{2} \mathrm{P} / \mathrm{CFs}$ and $\mathrm{Co}_{2} \mathrm{P} / \mathrm{CoP} / \mathrm{CFs}$ show a relatively poor reversible specific capacity and rate properties (Fig S16, S17). This is due to the lower stoichiometry ratio of $\mathrm{P}$ in their crystalline phase. It is worth noting that there is a pronounced difference in electrochemical performance between $\mathrm{Co}_{2} \mathrm{P} / \mathrm{CFs}$, Co-P-M-0.5 and Co-P-N-0.5 (Fig S17, S18), highlighting that our porous framework can promote a high degree of contact between the electrode and electrolytes, and also buffer the mechanical stress for enhanced lithium storage.
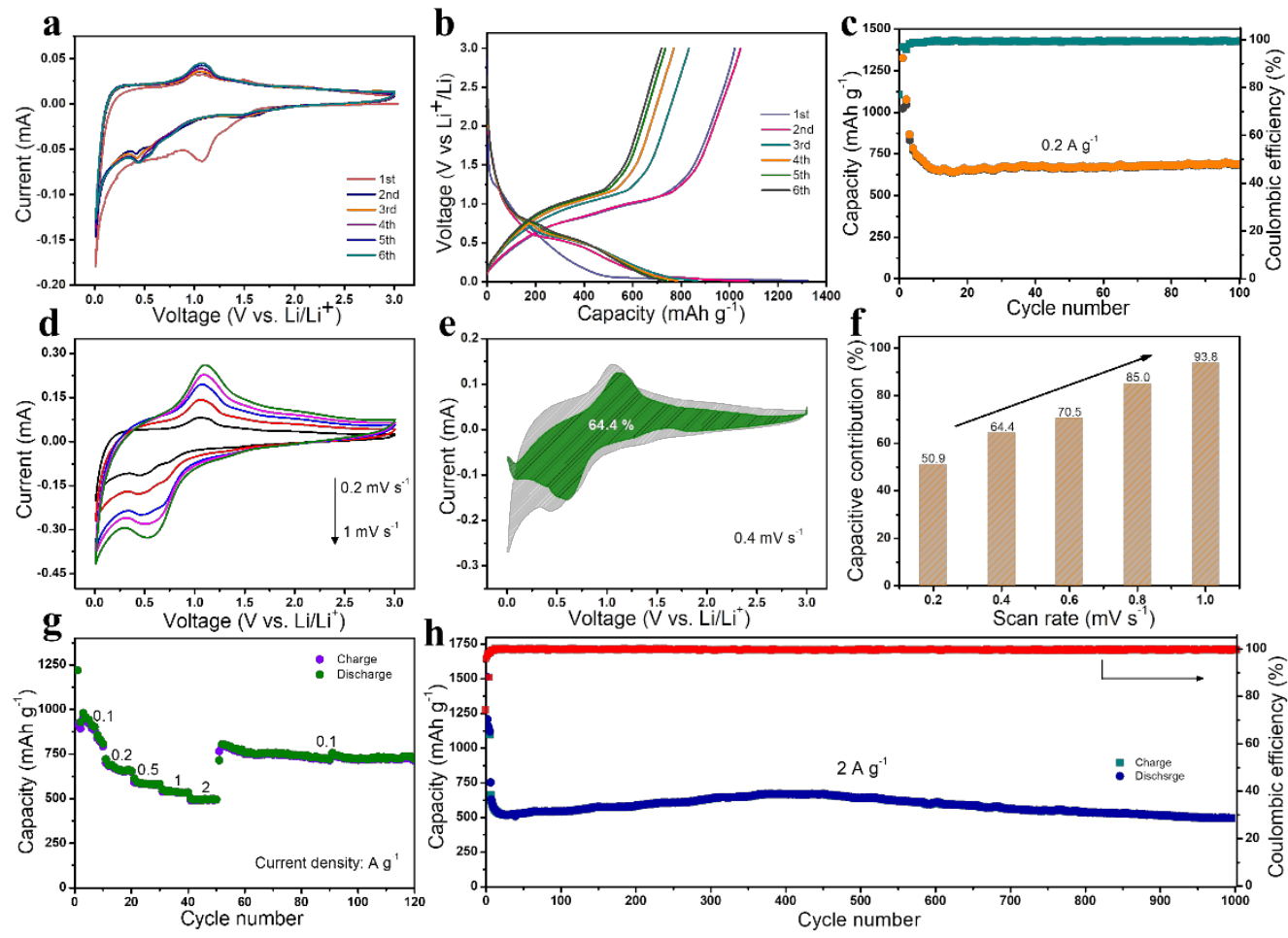

Fig 7. Lithium-storage performance for the $\mathrm{CoP} / \mathrm{CF}$ s porous framework: (a) $\mathrm{CV}$ curves,

(b) charge-discharge curves at $0.2 \mathrm{~A} \mathrm{~g}^{-1}$, (c) cycling performance at $0.2 \mathrm{~A} \mathrm{~g}^{-1}$ (d) $\mathrm{CV}$ 
curves at different scan rates, (e) ratio of capacitive contribution at $0.4 \mathrm{mV} \mathrm{s}^{-1}$, (f) contribution ratio of capacitive capacity in $\mathrm{CoP} / \mathrm{CFs}$ at different scan rates. $(\mathrm{g})$ rate performance at different current densities, (h) long cycling performance at $2 \mathrm{~A} \mathrm{~g}^{-1}(0.1$ $\mathrm{A} \mathrm{g}^{-1}$ for the first two cycles).

\section{CONCLUSION}

We have demonstrated an effective methodology that relies on a functional semi-IPN hydrogel as a precursor. Agar/PVPA- $\mathrm{M}^{\mathrm{n}+}$ semi-IPN hydrogels can serve as selfassembly/sacrificing templates to accomplish 3D space confinement, resulting in phase-control of a porous framework of $\mathrm{Co}_{\mathrm{x}} \mathrm{P}$. PVPA is identified as a prominent phosphorous source due to its strong metal complexation ability and thermal stability, and the PVPA chain promotes the formation of crystalline domains during in-situ phosphidation. The same strategy is also successfully applied to $\mathrm{Fe}_{2} \mathrm{P}, \mathrm{Ni}_{2} \mathrm{P}$ and $\mathrm{Cu}_{3} \mathrm{P}$, suggesting the extension of our methodology to the fabrication of other inorganic materials with different metals, revealing that $\mathrm{CoP} / \mathrm{CFs}$ and $\mathrm{Co}_{2} \mathrm{P} / \mathrm{CF}$ s are competitive candidates for application in LIBs, delivering superior lithium storage performances. More greatly, this phosphidation methodology envisions a new outlook on an integrated exploitation of essential functional hydrogels for the creation of inorganic nanomaterials towards sustainable energy development. 


\section{AUTHOR INFORMATION}

\section{Corresponding Author}

*Email: xji@csu.edu.cn, d.silvester-dean@curtin.edu.au, xiaoyisun@csu.edu.cn.

\section{ACKNOWLEDGMENT}

This work was financially supported by National Natural Science Foundation of China (51622406, 21673298, 21574147, 21374133), National Key Research and

Development Program of China (2017YFB0102000, 2018YFB0104200, 2018YFC1901605), Hunan Provincial Science and Technology Plan (2017TP1001, 2016TP1009), Hunan Provincial Natural Science Foundation of China (2018JJ2483), Innovation-Driven Project of Central South University (2017CX020), National Postdoctoral Program for Innovative Talents (BX201600192), Fundamental Research Funds for the Central Universities of Central South University (2019zzts431, 2019zzts433). 


\section{REFERENCES}

1 Su, J.; Zhou, J.; Wang, L.; Liu, C.; Chen, Y. Science bulletin 2017, 62 (9), 633-644.

2 Liu, Z.; Yang, S.; Sun, B.; Chang, X.; Zheng, J.; Li, X. Angewandte Chemie 2018, $130(32), 10344-10348$

3 Anantharaj, S.; Ede, S. R.; Sakthikumar, K.; Karthick, K.; Mishra, S.; Kundu, S. Acs Catalysis 2016, 6 (12), 8069-8097.

4 Callejas, J. F.; Read, C. G.; Roske, C. W.; Lewis, N. S.; Schaak, R. E. Chemistry of Materials 2016, 28 (17), 6017-6044.

5 Zang, Y.; Niu, S.; Wu, Y.; Zheng, X.; Cai, J.; Ye, J.; Xie, Y.; Liu, Y.; Zhou, J.; Zhu, J. Nature communications 2019, 10 (1), 1217.

6 Shi, D.; Zheng, R.; Sun, M. J.; Cao, X.; Sun, C. X.; Cui, C. J.; Liu, C. S.; Zhao, J.; Du, M. Angewandte Chemie International Edition 2017, 56 (46), 14637-14641.

7 Oyama, S. T.; Gott, T.; Zhao, H.; Lee, Y.-K. Catalysis Today 2009, 143 (1-2), 94-107. 8 Shi, Y.; Zhang, B. Chemical Society Reviews 2016, 45 (6), 1529-1541.

9 Wu, T.; Zhang, C.; Zou, G.; Hu, J.; Zhu, L.; Cao, X.; Hou, H.; Ji, X. Science China Materials 2019, 62 (8), 1127-1138.

10 Liu, J.; Meyns, M.; Zhang, T.; Arbiol, J.; Cabot, A.; Shavel, A. Chemistry of Materials 2018, 30 (5), 1799-1807.

11 Mundy, M. E.; Ung, D.; Lai, N. L.; Jahrman, E. P.; Seidler, G. T.; Cossairt, B. M. Chemistry of Materials 2018, 30 (15), 5373-5379.

12 Xu, X.; Liu, J.; Liu, Z.; Wang, Z.; Hu, R.; Liu, J.; Ouyang, L.; Zhu, M. Small 2018, $14(30), 1800793$. 
13 Ge, X.; Li, Z.; Yin, L. Nano Energy 2017, 32, 117-124.

14 Hou, H.; Shao, L.; Zhang, Y.; Zou, G.; Chen, J.; Ji, X. Advanced science 2017, 4 (1), 1600243.

15 Zou, G.; Hou, H.; Foster, C. W.; Banks, C. E.; Guo, T.; Jiang, Y.; Zhang, Y.; Ji, X. Advanced Science 2018, 5 (7), 1800241.

16 Zhang, T.-Q.; Liu, J.; Huang, L.-B.; Zhang, X.-D.; Sun, Y.-G.; Liu, X.-C.; Bin, D.-

S.; Chen, X.; Cao, A.-M.; Hu, J.-S. Journal of the American Chemical Society 2017, $139(32), 11248-11253$.

17 Ge, P.; Hou, H.; Cao, X.; Li, S.; Zhao, G.; Guo, T.; Wang, C.; Ji, X. Advanced Science 2018, 5 (6), 1800080.

18 Schlesinger, M. E. Chemical reviews 2002, 102 (11), 4267-4302.

19 Ha, D.-H.; Moreau, L. M.; Bealing, C. R.; Zhang, H.; Hennig, R. G.; Robinson, R. D. Journal of Materials Chemistry 2011, 21 (31), 11498-11510.

20 Voorhaar, L.; Hoogenboom, R. Chemical Society Reviews 2016, 45 (14), 4013-4031.

21 Zhang, Y. S.; Khademhosseini, A. Science 2017, 356 (6337), eaaf3627.

22 Li, J.; Wei, H.; Yu, P.; Geng, L. F.; Zhu, L.; Cao, X.; Pang, H.; Liu, C.-S. Chemical Communications 2019.

23 Liu, Y.; Zhang, K.; Ma, J.; Vancso, G. J. ACS applied materials \& interfaces 2016, $9(1), 901-908$.

24 Ngwabebhoh, F. A.; Gazi, M.; Oladipo, A. A. Chemical Engineering Research and Design 2016, 112, 274-288.

25 Hou, H.; Banks, C. E.; Jing, M.; Zhang, Y.; Ji, X. Advanced Materials 2015, 27 (47), 
7861-7866.

26 Wu, H.; Cao, Y.; Su, H.; Wang, C. Angewandte Chemie International Edition 2018, $57(5), 1361-1365$.

27 Zhao, F.; Bae, J.; Zhou, X.; Guo, Y.; Yu, G. Advanced Materials 2018, 30 (48), 1801796.

28 Shi, Y.; Zhou, X.; Zhang, J.; Bruck, A. M.; Bond, A. C.; Marschilok, A. C.; Takeuchi, K. J.; Takeuchi, E. S.; Yu, G. Nano letters 2017, 17 (3), 1906-1914.

29 Van Der Vliet, D. F.; Wang, C.; Tripkovic, D.; Strmcnik, D.; Zhang, X. F.; Debe, M. K.; Atanasoski, R. T.; Markovic, N. M.; Stamenkovic, V. R. Nature materials 2012, 11 (12), 1051.

$30 \mathrm{Fu}$, J. Journal of Materials Chemistry B 2019, 7 (10), 1523-1525.

31 Rivas, B. L.; Pereira, E.; Gallegos, P.; Homper, D.; Geckeler, K. E. Journal of applied polymer science 2004, 92 (5), 2917-2922.

32 Zhang, W.; Bao, X.; Guo, X.; Wang, X. Catalysis Letters 1999, 60 (1-2), 89-94.

33 Zhang, W.; Ma, D.; Han, X.; Liu, X.; Bao, X.; Guo, X.; Wang, X. Journal of Catalysis 1999, $188(2), 393-402$.

34 Li, D.; Yang, D.; Yang, X.; Wang, Y.; Guo, Z.; Xia, Y.; Sun, S.; Guo, S. Angewandte Chemie International Edition 2016, 55 (51), 15925-15928.

35 Mitrev, Y.; Simova, S.; Jeannerat, D. Chemical Communications 2016, 52 (31), 5418-5420.

36 Carenco, S.; Hu, Y.; Florea, I.; Ersen, O.; Boissière, C.; Mézailles, N.; Sanchez, C. Chemistry of Materials 2012, 24 (21), 4134-4145. 
37 Moreau, L. M.; Ha, D.-H.; Zhang, H.; Hovden, R.; Muller, D. A.; Robinson, R. D. Chemistry of Materials 2013, 25 (12), 2394-2403.

38 Bingöl, B.; Meyer, W. H.; Wagner, M.; Wegner, G. Macromolecular rapid communications 2006, 27 (20), 1719-1724.

39 Göktepe, F.; Çelik, S. Ü.; Bozkurt, A. Journal of Non-Crystalline Solids 2008, 354 (30), 3637-3642.

40 Braybrook, J. H.; Nicholson, J. W. Journal of Materials Chemistry 1993, 3 (4), 361 365.

41 Greish, Y.; Brown, P. Journal of Materials Science: Materials in Medicine 2001, 12 (5), 407-411.

42 Yu, J.; Wu, X.; Zhong, Y.; Yang, G.; Ni, M.; Zhou, W.; Shao, Z. Chemistry-A European Journal 2018, 24 (52), 13800-13806.

43 Adam, A.; Suliman, M. H.; Siddiqui, M. N.; Yamani, Z. H.; Merzougui, B.; Qamar, M. ACS applied materials \& interfaces 2018, 10 (35), 29407-29416.

44 Xia, G.; Su, J.; Li, M.; Jiang, P.; Yang, Y.; Chen, Q. Journal of Materials Chemistry A 2017, 5 (21), 10321-10327.

45 Zhou, X.; Gao, H.; Wang, Y.; Liu, Z.; Lin, J.; Ding, Y. Journal of Materials Chemistry A 2018, 6 (30), 14939-14948.

46 Guo, T.; Liao, H.; Ge, P.; Zhang, Y.; Tian, Y.; Hong, W.; Shi, Z.; Shao, C.; Hou, H.; Ji, X. Materials Chemistry and Physics 2018, 216, 58-63.

47 Zhang, W.; Xu, X.; Zhang, C.; Yu, Z.; Zhou, Y.; Tang, Y.; Wu, P.; Guo, S. Small Methods 2017, 1 (8), 1700167. 
48 Nieckarz, D.; Szabelski, P. Chemical communications 2018, 54 (63), 8749-8752.

49 Wang, T.; Sun, Y.; Zhang, L.; Li, K.; Yi, Y.; Song, S.; Li, M.; Qiao, Z. A.; Dai, S. Advanced Materials 2019, 31 (16), 1807876.

50 Tong, D.-G.; Chu, W.; Luo, Y.-Y.; Ji, X.-Y.; He, Y. Journal of Molecular Catalysis A: Chemical 2007, 265 (1-2), 195-204.

51 Yang, N.; Cheng, H.; Liu, X.; Yun, Q.; Chen, Y.; Li, B.; Chen, B.; Zhang, Z.; Chen, X.; Lu, Q. Advanced Materials 2018, 30 (39), 1803234.

52 Chen, D.-M.; Tian, J.-Y.; Liu, C.-S.; Du, M. Chemical Communications 2016, 52 (54), 8413-8416.

53 Chen, D.-M.; Tian, J.-Y.; Wang, Z.-W.; Liu, C.-S.; Chen, M.; Du, M. Chemical Communications 2017, 53 (77), 10668-10671.

54 Shi, D.; Zheng, R.; Liu, C.-S.; Chen, D.-M.; Zhao, J.; Du, M. Inorganic chemistry 2019.

55 Augustyn, V.; Come, J.; Lowe, M. A.; Kim, J. W.; Taberna, P.-L.; Tolbert, S. H.; Abruña, H. D.; Simon, P.; Dunn, B. Nature materials 2013, 12 (6), 518.

56 Xu, Y.; Zhang, C.; Zhou, M.; Fu, Q.; Zhao, C.; Wu, M.; Lei, Y. Nature communications 2018, $9(1), 1720$.

57 Simon, P.; Gogotsi, Y.; Dunn, B. Science 2014, 343 (6176), 1210-1211.

58 Ge, P.; Hou, H.; Li, S.; Yang, L.; Ji, X. Advanced Functional Materials 2018, 28 (30), 1801765. 